\title{
The Model for Location Routing Problem with Roaming Delivery Locations
}

\author{
Stefanus Ivan Laksono ${ }^{a^{*}}$, Y. M. Kinley Aritonang a, Julius Dharma Lesmono b \\ a Department of Industrial Technology, Parahyangan Catholic University, Bandung, Indonesia \\ b Department of Mathematics, Parahyangan Catholic University, Bandung, Indonesia \\ * Corresponding author: stefanusivanlaksono@gmail.com
}

\section{ARTICLE INFO}

\section{Article history}

Received April 13, 2020

Revised July 20, 2020

Accepted August 7, 2020

Available Online August 30, 2020

Keywords

Vehicle routing

Location-routing

Trunk delivery

Roaming delivery locations

Last-mile

\section{ABSTRACT}

The Location Routing Problem with Roaming Delivery Locations (LRPRDL) is a model that represents company activities in delivering products to final customers. Direct delivery to final customers has increased significantly over the growth of ecommerce in the world. E-commerce or business-to-customer companies are urged to increase their last-mile distribution efficiency to survive in the global competition. For that purpose, the LRPRDL model was proposed to increase the efficiency of the company's last-mile distribution. The model aims to minimize the sum of open depots and transportation costs by determining the number and location of depots and the shipping routes. The LRPRDL was implemented in an instance with four depot candidates, 15 customers, and six vehicles. The instance was solved to the optimality by using a public solver Gurobi. Furthermore, this research conducted a sensitivity analysis on the open depots and fuel costs, customer demand, and radius. The study indicated that customer's demand and radius have a significant impact on the purchase decision.

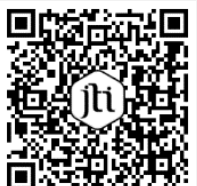

This is an open-access article under the CC-BY-SA license.

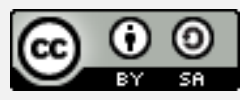

\section{Introduction}

The Location Routing Problem with Roaming Delivery Locations (LRPRDL) is a model that delivers products to final customers, especially in e-commerce and Businessto-Customer companies (B2C). These companies have developed rapidly and are increasingly important in many countries [1]. Based on a survey in 2016, online purchases have surpassed in-store purchases for the first time in the US. As many as 24.74 million people in Indonesia made online purchases in 2017; that number increased significantly to 107 million in 2019. As a result, the delivery of products directly to final customers has increased tremendously along with the growth of e-commerce [2]. This situation opens up new challenges for companies to manage the higher complexity of the distribution activities directly called last-mile [3].

Last-mile is the last stretch of order fulfillment to deliver products ordered online to the final consumer [4]. In recent years, last-mile is becoming increasingly complex and strategic for manufacturers and retailers [5]. A survey conducted in the US revealed that transportation costs contributed to $49 \%$ of the total supply chain costs [6]. With increasing 
transportation costs and longer lead times, last-mile is expected to contribute up to $75 \%$ of total supply chain costs [7]. Therefore, last-mile is regarded as one of the most expensive, least efficient, and most polluting portions of the entire supply chain step [8]. Last-mile efficiency has recently received increasing attention and has become the main focus of companies' improvement to survive in global competition [9]. One way is by practicing the LRPRDL model, which combines the concept of Location Routing Problem (LRP) and Vehicle Routing Problem with Roaming Delivery Locations (VRPRDL).

VRPRDL is one variant of the Vehicle Routing Problem (VRP) related to last-mile distribution [10]. VRPRDL is formed from a combination of the Vehicle Routing Problem with Time Window (VRPTW) [11] and the Generalized Vehicle Routing Problem (GVRP) [12], [13], [14]. VRPRDL determines vehicle routing by considering the use of trunk delivery based on the customer's itinerary. Trunk delivery allows companies to deliver goods directly to the customer's car trunk at a certain customer location. This innovation is attractive because it can produce a more feasible and economic scheme and avoid a second or third delivery [15]. Ozbaygin et al. [16] and Ozbaygin and Savelsberg [17] show that the implementation of trunk delivery can reduce $65 \%$ on transportation costs depending on the depot location. Based on that research, trunk delivery has a higher potential to be used in the future for improving last-mile distribution efficiency. Amazon has implemented this innovation since 2017 through the Amazon Key In-Car Delivery service. The development continues to be carried out, and some researchers have incorporated stochastic travel times into VRPRDL [18], [19].

It is well known that depot location and vehicle routing are interrelated areas [20]. However, the classical location problem ignores vehicle routing when locating depots and may increase distribution costs [21]. Many practitioners often solve the problem by separating depot location and vehicle routing. However, they are aware of the potential danger [22]. For that purpose, the LRP model was developed to accommodate depot locations and vehicle routing determination. Another study conducted by Kevin, Aritonang, and Lesmono [23] also successfully integrated the two decision-making areas. Nagy and Salhi [24] found that location routing could decrease costs over a long planning horizon. Perl and Daskin [25], Tuzun and Burke [26], and Albareda-sambola [27] indicate variations of the LRP model, which differ in their constraint and objective functions. The development of the LRP model that incorporated generalizations was conducted by Glicksman and Penn [28] and Harks, König, and Matuschke [29]. In contrast, those that incorporated Time Window were analyzed by Gündüz [30], Zarandi et al. [31], and Belenguer et al. [32].

The growth of e-commerce has led to a significant increase in last-mile delivery. The development of a model that can improve the company's last-mile delivery efficiency is seen as one way to resolve the issue. Based on the previous knowledge, there is no model like LRPRDL that combines the concept of LRP and VRPRDL. It has been proven that determining the location of depots and vehicle routing cannot be done separately. Using the LRP model is expected to simultaneously solve both problems, resulting in a lower total of transportation and open depot costs. On the other hand, the implementation of trunk delivery from VRPRDL can reduce vehicle mileage, impacting transportation costs. Overall, the use of the model LRPRDL is expected to improve its last-mile distribution system's efficiency.

This paper was structured into four sections. The first section dealt with the introduction. Section two displayed the method that presented assumptions and notations, mathematical formulation, data collection, and experimental procedure. Results and discussion were presented in section three. Finally, the conclusion was projected in section four. 


\section{Methods}

\subsection{Assumptions and Notations}

The assumptions of the model comprise of 1) Travel time and customer demand are deterministic; 2) There is no distinction between travel time of vehicles and customers; 3) The candidate depot locations have been determined or in another word, the solution space is discrete; 4) Customer's itineraries are known; 5) Customer's house must be the first and the last location in each customer's itinerary; 6) Each customer has unique locations in their itinerary. The notations used in this model include:

$D \quad$ : a set of candidate depot locations

$N \quad$ : a set of all customer locations

$V \quad: \quad$ a set of all locations (union of candidate depot and customer locations)

$E_{D N} \quad:$ all links connecting one depot to one customer location

$E_{N} \quad:$ all links connecting two different customer locations

C : a set of customers

$N_{c} \quad$ : set of a geographic profile of customer $c$

$K \quad:$ a set of vehicles

$Q \quad: \quad$ capacity of each vehicle

$d_{c} \quad:$ demand from customer $c$

$q_{i} \quad:$ capacity of depot $i$

$f_{i} \quad:$ open depot cost on location $i$

$t_{i j} \quad:$ travel time from $i$ to $j$

$w_{i j} \quad$ : travel cost from $i$ to $j$

$\left[a_{i}^{c}, b_{i}^{c}\right]$ : time window of customer $c$ on location $i$

To formulate the LRPRDL, the following decision variables are necessary:

$x_{i j k} \in[0,1]:$ indicates whether vehicle $k \in K$ uses arc $(i, j) \in E$

$y_{i} \in[0,1]:$ indicates whether a depot is opened in location $d \in D$

$z_{i c} \in\{0,1\}$ : indicates whether customer $j \in J$ is served by an open depot in location $d \in$ $D$

$\tau_{c k} \in[0, T]$ : time of departure of vehicle $k \in K$ after service to customer $c \in C$ at any of its location in $N_{c}$

$R_{c k} \in[0, Q]: \quad$ cargo remaining in vehicle $k \in K$ after service to customer $c \in C$

\subsection{Mathematical Formulation}

The LRPRDL is based on the LRP model by Albareda-sambola [27] modified using the VRPRDL model by Reyes, Savelsbergh, and Toriello [10]. The development of this model is carried out by selecting constraints that still conform to the LRPRDL model, adjusting variables in some constraints, and removing constraints that have the same function as the existing constraints, and adding new constraints. The formulation of LRPRDL is presented below.

$$
\begin{aligned}
& \min _{x, y, z, \tau, R} \sum_{i \in D} f_{i} y_{i}+\sum_{k \in K} \sum_{i, j \in E} w_{i j} x_{i j k} \\
& \text { s.t. } \quad \sum_{k \in K} \sum_{i \in N_{c}} \sum_{j \in V \backslash(i)} x_{i j k}=1
\end{aligned}
$$




$$
\begin{array}{lr}
\sum_{j \in V \backslash(i)} x_{i j k}=\sum_{j \in V \backslash(i)} x_{j i k} & \forall i \in V \\
\sum_{i \in D} \sum_{j \in N} x_{i j k} \leq 1 & \forall k \in K \\
\sum_{i \in D} \sum_{j \in D} \sum_{k \in K} x_{i j k}=0 & \forall k \in K \\
\sum_{c \in C} d_{c} z_{i c}-q_{i} y_{i} \leq 0 & \forall i \in D \\
0 \leq R_{c k} \leq Q-d_{c} & \forall c \in C \\
R_{c k}+Q\left(1-\sum_{i \in N_{c}} \sum_{j \in N_{c^{\prime}}} x_{i j k}\right) \geq d_{c^{\prime}}+R_{c^{\prime} k} & \forall k \in K \\
\sum_{i \in N_{c}} a_{i}^{c} \sum_{j \in V \backslash\{i\}} x_{i j k} \leq \tau_{c k} \leq \sum_{i \in N_{c}} b_{i}^{c} \sum_{j \in V \backslash\{i\}} x_{i j k} & \forall c \in C \cup\{D\} \\
\tau_{c k}+\sum_{i \in N_{c}} \sum_{j \in N_{c^{\prime}}} t_{i j} x_{i j k} \leq \tau_{c^{\prime} k}+T\left(1-\sum_{i \in N_{c}} \sum_{j \in N_{c^{\prime}}} x_{i j k}\right) & \forall c^{\prime} \in C \backslash\{c\} \\
\sum_{m \in V}\left(x_{i m k}+\sum_{n \in N_{c}} x_{m n k}\right) \leq z_{i c}+1 & \forall k \in K \\
\sum_{i \in D} \sum_{c \in C} z_{i c}=|C| & \forall c \in C \\
a_{1}^{c}=0 ; b_{k}^{c}=T & \forall k \in K \\
a_{l}^{c}=b_{l-1}^{c}+t_{i_{l-1}, i}{ }_{l}^{c} & \forall c \in C \cup\{D\} \\
& \forall c^{\prime} \in C \backslash\{c\} \\
& \forall k \in K \\
& \forall i \in D \\
& \forall c \in C \\
& \forall k \in K \\
& \forall c \in C \\
& l=2, \ldots, k
\end{array}
$$

The objective function is to (1) minimize the sum of open depots and transportation costs. Constraint (2) ensures that each customer is visited only once. Constraint (3) describes the flow of conservation for every location. Furthermore, constraint (4) limits the uses of vehicles in the establishment of delivery routes. For every open depot, each vehicle can only be used at most once. Constraint (5) confirms that routes between depots are not formed. The depot and vehicle capacity limitations are enforced by constraints (6) and (7), while constraint (8) guarantees that remaining cargo and customer demand are consistent. Constraints (9) and (10) serve a similar function for the time windows. Constraints (8) and (10) also function to eliminate sub-tours. Constraint (11) assures that a customer is only served by a vehicle assigned to the same open depot. Constraint (12) ascertains that each customer is only served by one depot. Constraint (13) assures that the fulfillment of customer demand starts at time 0 and ends at time T. Constraint (14) signifies that the movement of customer's vehicles from one location to another incurs the same travel time as the delivery vehicles.

Fig. 1 illustrates the LRPRDL model in an instance with three candidate depots, eight customers, and a total of 30 locations. 


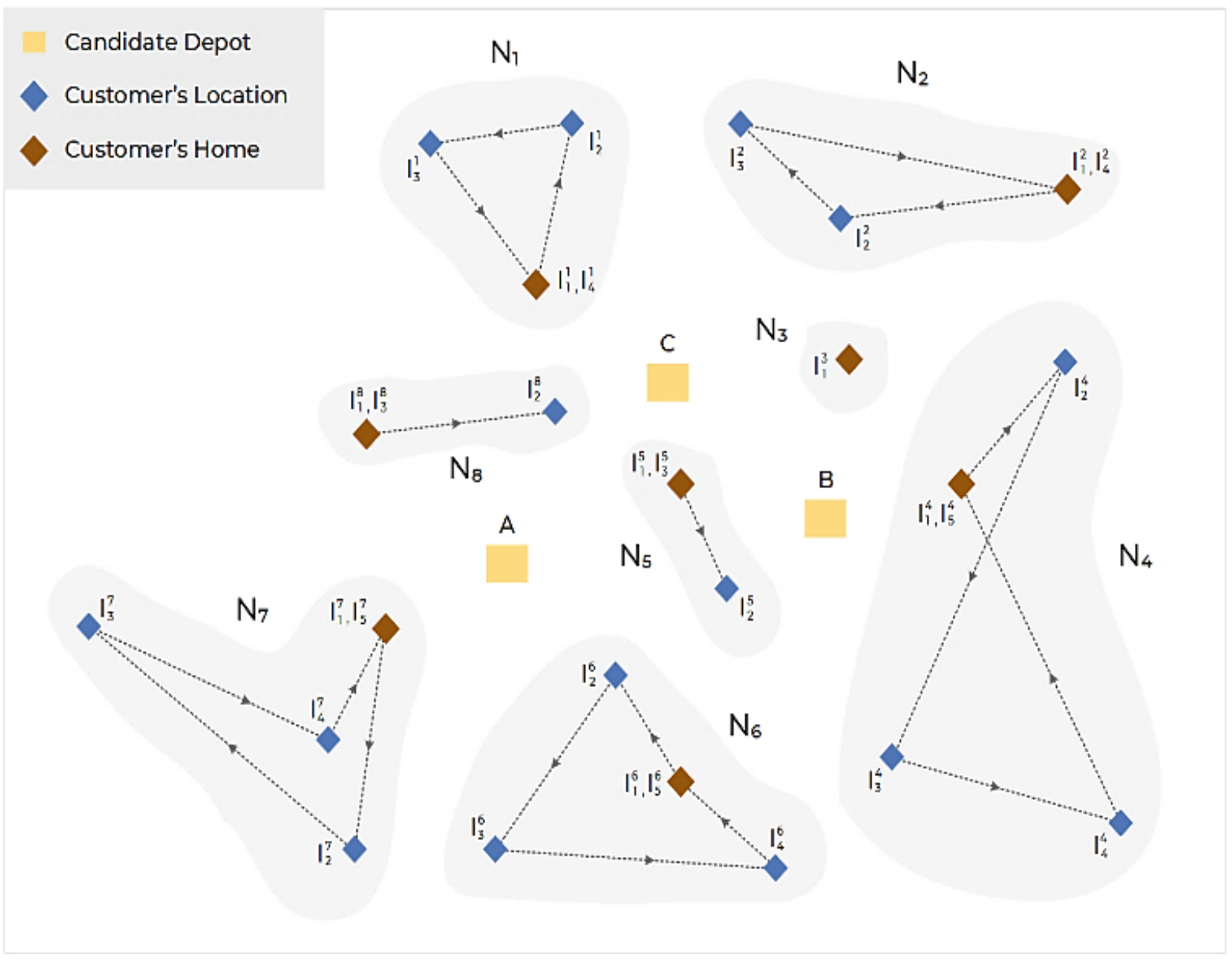

Fig. 1 Illustration of LRPRDL Model

\subsection{Data Collection}

The LRPRDL model was implemented in an instance; it comprised four depot candidates. All of them had the same cost and capacity. The open depot cost was estimated based on warehouse rental data in Bandung, Indonesia. It was assumed that the working day in the company was 300 days. The cost of renting a warehouse with a building area of around $150 \mathrm{~m}^{2}$ had a price of approximately 120,000,000 IDR per year or 400,000 IDR per working day. Based on these data, the set depot capacity was 300 units, and the open depot cost was 400,000 IDR. Fifteen customers had demand with an average of 25 units and a standard deviation of 8 units. Their locations were spread out in a circular area with a center at $(0,0)$ and a maximum radius of $32 \mathrm{~km}$. The time window for each location was randomized based on the remaining time after reducing the customer total travel time between locations. All customer demands had to be fulfilled before the deadline $T$ which value was 600 minutes. Table 1 contains detailed information about depot candidates and customer demands, coordinates, and time windows.

The company has six (6) vehicles that use biodiesel as a fuel. The price of biodiesel is 9,300 IDR per liter. We assumed that the ratio of vehicle fuel use (in liters) to vehicle mileage (in $\mathrm{km}$ ) was 1:7. Therefore, the fuel cost of 1,500 IDR per $\mathrm{km}$ was set. During the delivery of goods, the vehicle was predicted to move at a speed of $30 \mathrm{~km}$ per hour. All of the vehicles had the same maximum capacity of 100 units. 
Table 1. Depot and Customer Data

\begin{tabular}{|c|c|c|c|c|c|}
\hline Customer & Demand & Location & Coordinate & $\begin{array}{c}\text { Start } \\
\text { (minute) }\end{array}$ & $\begin{array}{c}\text { End } \\
\text { (minute) }\end{array}$ \\
\hline \multirow{4}{*}{0} & \multirow{4}{*}{0} & $\mathrm{~A}$ & $(-4,10)$ & 0 & - \\
\hline & & B & $(-5,-13)$ & 0 & - \\
\hline & & $\mathrm{C}$ & $(10,-3)$ & 0 & - \\
\hline & & $\mathrm{D}$ & $(2,-7)$ & 0 & - \\
\hline \multirow{5}{*}{1} & \multirow{5}{*}{25} & 1 & $(0,28)$ & 0 & 47 \\
\hline & & 2 & $(-16,-19)$ & 147 & 181 \\
\hline & & 3 & $(-1,-28)$ & 217 & 252 \\
\hline & & 4 & $(-27,0)$ & 330 & 373 \\
\hline & & 5 & $(0,28)$ & 451 & 600 \\
\hline 2 & 18 & 6 & $(20,-23)$ & 0 & 600 \\
\hline \multirow{4}{*}{3} & \multirow{4}{*}{12} & 7 & $(-9,15)$ & 0 & 184 \\
\hline & & 8 & $(7,23)$ & 220 & 236 \\
\hline & & 9 & $(0,-10)$ & 304 & 425 \\
\hline & & 10 & $(-9,15)$ & 479 & 600 \\
\hline \multirow{3}{*}{4} & \multirow{3}{*}{30} & 11 & $(-11,-22)$ & 0 & 14 \\
\hline & & 12 & $(19,-5)$ & 84 & 358 \\
\hline & & 13 & $(-11,-22)$ & 428 & 600 \\
\hline \multirow{4}{*}{5} & \multirow{4}{*}{26} & 14 & $(-13,9)$ & 0 & 30 \\
\hline & & 15 & $(-2,-30)$ & 112 & 222 \\
\hline & & 16 & $(2,-16)$ & 252 & 423 \\
\hline & & 17 & $(-13,9)$ & 483 & 600 \\
\hline \multirow{4}{*}{6} & \multirow{4}{*}{10} & 18 & $(-9,17)$ & 0 & 16 \\
\hline & & 19 & $(-20,11)$ & 42 & 137 \\
\hline & & 20 & $(-4,-22)$ & 211 & 310 \\
\hline & & 21 & $(-9,17)$ & 390 & 600 \\
\hline \multirow{4}{*}{7} & \multirow{4}{*}{18} & 22 & $(17,18)$ & 0 & 166 \\
\hline & & 23 & $(-29,-11)$ & 276 & 380 \\
\hline & & 24 & $(12,-16)$ & 464 & 500 \\
\hline & & 25 & $(17,18)$ & 570 & 600 \\
\hline Customer & Demand & Location & Coordinate & $\begin{array}{c}\text { Start } \\
\text { (minute) }\end{array}$ & $\begin{array}{c}\text { End } \\
\text { (minute) }\end{array}$ \\
\hline \multirow{3}{*}{8} & \multirow{3}{*}{34} & 26 & $(-17,0)$ & 0 & 195 \\
\hline & & 27 & $(22,18)$ & 281 & 366 \\
\hline & & 28 & $(-17,0)$ & 452 & 600 \\
\hline \multirow{4}{*}{9} & & 29 & $(27,-5)$ & 0 & 18 \\
\hline & & 30 & $(25,13)$ & 56 & 362 \\
\hline & 14 & 31 & $(11,1)$ & 400 & 521 \\
\hline & & 32 & $(27,-5)$ & 557 & 600 \\
\hline & & 33 & $(18,-4)$ & 0 & 126 \\
\hline 10 & 17 & 34 & $(-28,0)$ & 220 & 441 \\
\hline & & 35 & $(18,-4)$ & 535 & 600 \\
\hline & & 36 & $(0,-20)$ & 0 & 19 \\
\hline & & 37 & $(-21,-9)$ & 67 & 242 \\
\hline 11 & 31 & 38 & $(16,-12)$ & 318 & 380 \\
\hline & & 39 & $(0,-20)$ & 416 & 600 \\
\hline & & 40 & $(-27,-7)$ & 0 & 173 \\
\hline 12 & 19 & 41 & $(-20,0)$ & 193 & 240 \\
\hline 12 & 19 & 42 & $(-1,-18)$ & 294 & 331 \\
\hline & & 43 & $(-27,-7)$ & 389 & 600 \\
\hline & & 44 & $(-8,23)$ & 0 & 153 \\
\hline 13 & 33 & 45 & $(-5,2)$ & 197 & 408 \\
\hline & & 46 & $(-8,23)$ & 452 & 600 \\
\hline & & 47 & $(0,-13)$ & 0 & 147 \\
\hline 14 & 23 & 48 & $(22,13)$ & 221 & 226 \\
\hline 14 & 23 & 49 & $(-10,-2)$ & 304 & 419 \\
\hline & & 50 & $(0,-13)$ & 449 & 600 \\
\hline & & 51 & $(15,-8)$ & 0 & 106 \\
\hline 15 & 41 & 52 & $(3,8)$ & 146 & 393 \\
\hline & & 53 & $(15,-8)$ & 433 & 505 \\
\hline
\end{tabular}




\subsection{Experimental Procedures}

The LRPRDL and the instance were modeled using AMPL language. This research was designed to the optimality by using public solver Gurobi 9.0.0. The validation process of the LRPRDL model was measured by testing it on several instances with 3 to 5 depot candidates and 5 to 10 customers. Then, we conducted sensitivity analyses to determine the changes in the solution that occurred when the input of the parameters was changed. These parameters were selected because their values were fluctuating in the real world. Therefore, the sensitivity analysis was needed to anticipate parameter changes that might occur beyond projected control. The parameters included were fuel, open depots cost, customer demand, and radius. Fuel costs have changed regularly according to government policy. Open depot cost tends to increase its price every year. Customer demand and locations always change. Each sensitivity analysis only changes the value of one of those parameters at a time.

\section{Results and Discussion}

\subsection{Solutions}

The optimal solution was formulated within 3 hours and 51 minutes. To achieve the optimal solution, the company had to open two depots and provide four vehicles to fulfill all customer's demands. Depot B and C were selected, and each depot operated two vehicles. The optimal solution's total cost was 1,059,500 IDR with a transportation cost of 259,500 IDR and an open depot cost of 800,000 IDR. Table 2 contains the details of the optimal solution from the instance. The illustration is provided in Fig. 2.

Table 2. Optimal Solution

\begin{tabular}{clccc}
\hline \multirow{2}{*}{ Vehicle } & \multicolumn{1}{c}{ Routing } & $\begin{array}{c}\text { Load } \\
\text { (unit) }\end{array}$ & $\begin{array}{c}\text { Travel Distance } \\
\text { (km) }\end{array}$ & $\begin{array}{c}\text { Last Service } \\
\text { (minute) }\end{array}$ \\
\hline 1 & $\mathrm{~B}-6(20)-1(3)-12(42)-5(16)-3(9)-\mathrm{B}$ & 92 & 44 & 425 \\
\hline 2 & $\mathrm{~B}-8(26)-14(49)-13(45)-\mathrm{B}$ & 90 & 48 & 318 \\
\hline 3 & $\mathrm{C}-15(51)-4(12)-10(33)-\mathrm{C}$ & 88 & 24 & 126 \\
\hline 4 & $\mathrm{C}-11(38)-2(6)-7(24)-9(31)-\mathrm{C}$ & 81 & 57 & 521 \\
\hline
\end{tabular}

\subsection{Sensitivity Analysis}

Based on the previous research, a sensitivity analysis was tested by using different instances. The difference with our research was that we only exemplified one instance instead. This research changed only one parameter at a time. For parameters, the radius was tested by Reyes, Savelsbergh, and Toriello [10], and open depot cost was observed based on Gündüz [30]. The results of those two parameters were in line with previous research. Overall, the study found that customer demand and radius significantly impact the decision, but not for the open depot and fuel cost. The result of sensitivity analysis is displayed in Table 3.

The sensitivity analysis indicated that the change in fuel or open depot costs did not affect the optimal solution decisions. It happened because the open depot cost was too expensive compared to the total transportation costs. The company needed to pay 400,000 IDR to open a new depot, while the total transportation cost was only 259,000 IDR. However, the sensitivity of the fuel and open depot cost still requires more investigation for other instances with more customers and depot candidates. For every 10\%, a total cost difference in the fuel and open depot cost changed by $2.45 \%$ and $7.55 \%$, respectively.

The changes in customer demand could increase or decrease the number of vehicles or open depots used. If the total demand exceeds the open depot or vehicle capacity, then 
the decision will be changed and vice versa. It affects the total cost significantly due to the high cost of the open depot. In our case, a reduction in demand by $20 \%$ caused a decrease in total costs by $36.62 \%$ and completely changed the decision. For the cases of increased customer demand, the total cost did not increase significantly. The optimal solution was to use the same depot, although the vehicle routing and the number of vehicles were adjusted.

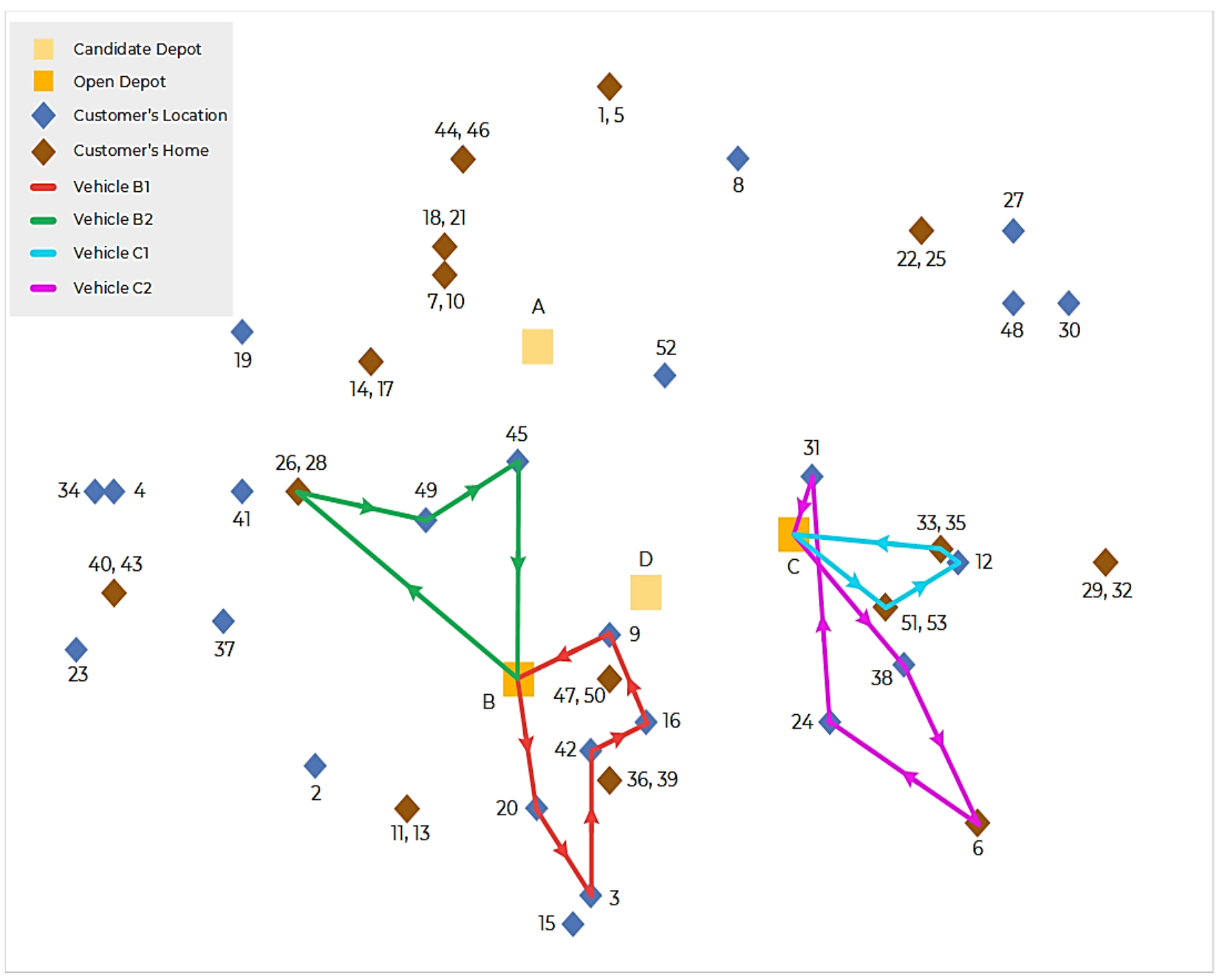

Fig. 2 Illustration of the Instance Optimal Solution

The changes have made all the customer locations closer or further from $(0,0)$ point in the radius sensitivity analysis. A smaller radius reduces the distance between locations and the tightness of each location's time windows and vice versa. Generally, changes in total costs are affected by transportation costs, not the open depot cost. It is possible if there are changes in vehicle routing or depot selection, but not the number of depots. From Table 3, we can see that a reduction of $50 \%$ in radius may change the selection of open depot to depot $\mathrm{C}$ and $\mathrm{D}$. This shows that depot $\mathrm{D}$ has a more strategic location to serve the customer, which location is closer to $(0,0)$ point. 
Table 3. Sensitivity Analysis Results

\begin{tabular}{ccccc}
\hline Percentage (\%) & Total Cost (IDR) & Total Cost Difference (\%) & Open Depot & Vehicle Used \\
\hline 0 & $1,059,500$ & 0 & B and C & 4 \\
\hline & & Fuel Cost & & \\
\hline-50 & 929,750 & -12.25 & B and C & 4 \\
\hline-30 & 981,650 & -7.35 & B and C & 4 \\
\hline 30 & $1,137,350$ & 7.35 & B and C & 4 \\
\hline 50 & $1,189,250$ & 12.25 & B and C & 4 \\
\hline & & & 4 \\
\hline-50 & 659,500 & Open Depot Cost & B and C & 4 \\
\hline-30 & 819,500 & -37.75 & B and C & B and C \\
\hline 50 & $1,299,500$ & -22.65 & B and C & 3 \\
\hline $1,459,500$ & 22.65 & & 4 \\
\hline-30 & & 37.75 & D & 5 \\
\hline 10 & 671,500 & Customer Demand & B and C & 5 \\
\hline 50 & $1,049,000$ & -36.62 & B and C & 4 \\
\hline
\end{tabular}

\section{Conclusion}

The LRPRDL model is a mathematical model for determining the depot location and vehicle delivery route by considering trunk delivery based on the customer itinerary that has been developed. The model was effective in minimizing the total of open depots and transportation costs. Sensitivity analysis was conducted on open depots and fuel costs, customer demand, and radius. The study revealed that customer's demand and radius have a significant impact on the optimal solution. For further research, we suggest developing another version of LRPRDL. The development of the LRPRDL model will use two index vehicle flow formulations so it can be predicted to generate less space. We recommend improving the LRPRDL formulation by adding stochastic travel times. Finally, applying heuristics or metaheuristics to the problem can help to find a good solution in a reasonable time.

\section{References}

[1] W. J. Weltevreden Jesse, "B2c e-commerce logistics: the rise of collection-anddelivery points in The Netherlands," International Journal of Retail \& Distribution Management, $\quad$ vol. $\quad 36, \quad$ pp. $\quad 638-660, \quad 2008$. https://dx.doi.org/10.1108/09590550810883487.

[2] I. Cárdenas, J. Beckers, and T. Vanelslander, "E-commerce last-mile in Belgium: Developing an external cost delivery index," Research in Transportation Business \& Management, vol. 24, pp. 2017. https://dx.doi.org/10.1016/j.rtbm.2017.07.006. 
[3] M. Janjevic and M. Winkenbach, "Characterizing urban last-mile distribution strategies in mature and emerging e-commerce markets," Transportation Research Part A: Policy and Practice, vol. 133, pp. 164-196, 2020. https://dx.doi.org/10.1016/j.tra.2020.01.003.

[4] W. T. Lim Stanley Frederick, X. Jin, and S. Srai Jagjit, "Consumer-driven ecommerce: A literature review, design framework, and research agenda on lastmile logistics models," International Journal of Physical Distribution \& Logistics Management, vol. 48, pp. 308-332, 2018. https://dx.doi.org/10.1108/IJPDLM-022017-0081.

[5] T. S. Harrington, J. Singh Srai, M. Kumar, and J. Wohlrab, "Identifying design criteria for urban system 'last-mile' solutions - a multi-stakeholder perspective," Production Planning \& Control, vol. 27, pp. 456-476, 2016. https://dx.doi.org/10.1080/09537287.2016.1147099.

[6] P. C. A. Rushton, and P. Baker, The Handbook of Logistics and Distribution Management: Understanding the Supply Chain, 4th ed. 2010.

[7] M. T. F. K. K. Boyer, and G. T. Hult, Extending the supply chain: how cutting-edge companies bridge the critical last mile into customers' homes, 1st ed. New York: AMACOM, 2005.

[8] D. Manerba, R. Mansini, and R. Zanotti, "Attended Home Delivery: reducing lastmile environmental impact by changing customer habits," IFAC-PapersOnLine, vol. 51, pp. 55-60, 2018. https://dx.doi.org/10.1016/j.ifacol.2018.06.199.

[9] R. Mangiaracina, A. Perego, A. Seghezzi, and A. Tumino, "Innovative solutions to increase last-mile delivery efficiency in B2C e-commerce: a literature review," International Journal of Physical Distribution \& Logistics Management, vol. 49, pp. 901-920, 2019. https://dx.doi.org/10.1108/IJPDLM-02-2019-0048.

[10] D. Reyes, M. Savelsbergh, and A. Toriello, "Vehicle routing with roaming delivery locations," Transportation Research Part C: Emerging Technologies, vol. 80, pp. 7191, 2017. https://dx.doi.org/10.1016/j.trc.2017.04.003.

[11] M. Desrochers, J. K. Lenstra, M. M. Savelsbergh, and F. Sourris, "Vehicle Routing With Time Windows: Optimization And Approximation. Vehicle Routing: Method And Studies. Studies In Management Science And Systems - Volume 16," 1987.

[12] G. Ghiani and G. Improta, "An efficient transformation of the generalized vehicle routing problem," European Journal of Operational Research, vol. 122, pp. 11-17, 2000. https://dx.doi.org/10.1016/S0377-2217(99)00073-9.

[13] P. C. Pop, I. Kara, and A. H. Marc, "New mathematical models of the generalized vehicle routing problem and extensions," Applied Mathematical Modelling, vol. 36, pp. 97-107, 2012. https://dx.doi.org/10.1016/j.apm.2011.05.037.

[14] B. Biesinger, B. Hu, and G. Raidl, "An Integer L-shaped Method for the Generalized Vehicle Routing Problem with Stochastic Demands," Electronic Notes in Discrete $\begin{array}{lllll}\text { Mathematics, } & \text { vol. } & 52, & \text { pp. }\end{array}$ https://dx.doi.org/10.1016/j.endm.2016.03.033.

[15] Y. He, M. Qi, F. Zhou, and J. Su, "An effective metaheuristic for the last mile delivery with roaming delivery locations and stochastic travel times," Computers \& Industrial Engineering, vol. 145, p. $106513,2020$. https://dx.doi.org/10.1016/j.cie.2020.106513.

[16] G. Ozbaygin, O. Ekin Karasan, M. Savelsbergh, and H. Yaman, "A branch-andprice algorithm for the vehicle routing problem with roaming delivery locations," Transportation Research Part B: Methodological, vol. 100, pp. 115-137, 2017. https://dx.doi.org/10.1016/j.trb.2017.02.003. 
[17] G. Ozbaygin and M. Savelsbergh, "An iterative re-optimization framework for the dynamic vehicle routing problem with roaming delivery locations," Transportation Research Part B: Methodological, vol. 128, pp. 207-235, 2019. https://dx.doi.org/10.1016/j.trb.2019.08.004.

[18] A. Lombard, S. Tamayo-Giraldo, and F. Fontane, "Vehicle Routing Problem with Roaming Delivery Locations and Stochastic Travel Times (VRPRDL-S)," Transportation Research Procedia, vol. 30, pp. 167-177, 2018. https://dx.doi.org/10.1016/j.trpro.2018.09.019.

[19] J. K. A. Sampaio, L. P. Veelenturf, and T. Van Woensel, "A Scenario-Based Approach for the Vehicle Routing Problem with Roaming Delivery Locations under Stochastic Travel Times," Optim. Online, 2019, [Online]. Available: , ed. http://www.optimization-online.org/DB_HTML/2019/05/7197.html.

[20] F. E. Maranzana, "On the Location of Supply Points to Minimize Transport Costs," OR, vol. 15, pp. 261-270, 1964. https://dx.doi.org/10.2307/3007214.

[21] S. Salhi and G. K. Rand, "The effect of ignoring routes when locating depots," European Journal of Operational Research, vol. 39, pp. 150-156, 1989. https://dx.doi.org/10.1016/0377-2217(89)90188-4.

[22] G. K. Rand, "Methodological Choices in Depot Location Studies," Journal of the Operational Research Society, vol. 27, pp. 241-249, 1976. https://dx.doi.org/10.1057/jors.1976.39.

[23] K. Kevin, Y. M. K. Aritonang, and J. D. Lesmono, "A Model to Choose Hub and Route Determination," 2019, vol. 20, p. $9,2019$. https://dx.doi.org/10.22219/JTIUMM.Vol20.No2.182-190.

[24] C. Salhi and G. Nagy," Stud. Locat. Anal., vol. 13, pp. 3-19, 1999, [Online]. Available: https://kar.kent.ac.uk/id/eprint/5249.

[25] J. Perl and M. S. Daskin, "A warehouse location-routing problem," Transportation Research Part B: Methodological, vol. 19, pp. 381-396, 1985. https://dx.doi.org/10.1016/0191-2615(85)90052-9.

[26] D. Tuzun and L. I. Burke, "A two-phase tabu search approach to the location routing problem," European Journal of Operational Research, vol. 116, pp. 87-99, 1999. https://dx.doi.org/10.1016/S0377-2217(98)00107-6.

[27] L. S. M. Albareda-sambola, " in Location Science, G. Laporte, S. Nickel, and F. S. da Gama, Eds. Springer International Publishing, 2015, pp. 399-418.

[28] H. Glicksman and M. Penn, "Approximation algorithms for group prize-collecting and location-routing problems," Discrete Applied Mathematics, vol. 156, pp. 32383247, 2008. https://dx.doi.org/10.1016/j.dam.2008.05.013.

[29] T. Harks, F. G. König, and J. Matuschke, "Approximation Algorithms for Capacitated Location Routing," Transportation Science, vol. 47, pp. 3-22, 2013. https://dx.doi.org/10.1287/trsc.1120.0423.

[30] H. I. Gündüz, "The Single-Stage Location-Routing Problem with Time Windows," Berlin, Heidelberg, 2011, pp. 44-58. https://dx.doi.org/10.1007/978-3-642-242649_4.

[31] M. H. Fazel Zarandi, A. Hemmati, S. Davari, and I. Burhan Turksen, "Capacitated location-routing problem with time windows under uncertainty," Knowledge-Based $\begin{array}{lllll}\text { Systems, } & \text { vol. } & 37, & \text { pp. } & 480-489,\end{array}$ https://dx.doi.org/10.1016/j.knosys.2012.09.007.

[32] J.-M. Belenguer, E. Benavent, C. Prins, C. Prodhon, and R. Wolfler Calvo, "A Branch-and-Cut method for the Capacitated Location-Routing Problem," Computers \& Operations Research, vol. 38, pp. 931-941, 2011. https://dx.doi.org/10.1016/j.cor.2010.09.019. 